\title{
Tailings dewatering with increased filtration rates and lowest filter cake moisture for filtered tailings stacking
}

\author{
J Hahn BOKELA GmbH, Germany
}

\begin{abstract}
The most commonly used dewatering technologies for the filtration of tailings from ore processing are pressure filters, filter presses, belt filters and rotary vacuum disc filters. The vacuum disc filter type in around 80\% of all applications is the most economical of these technologies in terms of capital and operating cost, especially when modern high performance disc filters are used.

The Boozer disc filter is a big diameter high performance vacuum disc filter that has set the pattern in a multitude of applications including the alumina industry and in dewatering coal slurries. In the past decade, this type of disc filter has established itself in applications of tailings dewatering, such as tailings from gold/copper, zinc and gold/silver mines. The reasons for its successful operation in tailings dewatering are: (a) high throughput and dewatering performance, (b) operational reliability even in the case of varying feed conditions, (c) simple and robust design, (d) ease of maintenance, (e) a small footprint. To achieve higher solids throughput rates, or to achieve the lowest possible filter cake moisture, HiBar filtration and HiBar steam pressure filtration offer new solutions in tailings dewatering. HiBar filtration and the HiBar steam pressure filtration are advanced continuous pressure filtration processes realised on rotary disc filters that are installed in a pressure vessel. The application of hyperbaric pressure of up to 6 bar (instead of a vacuum) ensures a high filtration rate and dewatering capability even with filter cakes of fine particles where high cake resistance and capillary forces in the cake must be overcome. With HiBar steam pressure filtration, the use of steam under special conditions improves demoisturing to the furthest extent, leading to the lowest values of moisture content. The drier HiBar filter cake improves the cake handling and disposal with steeper dumping slopes, resulting in reduced disposal area and improved safety of the disposal site.
\end{abstract}

Keywords: dewatering, vacuum disc filter, continuous pressure filtration, filter cake firmness

\section{Introduction}

For the treatment of tailings from ore processing and the production of paste backfill, filtration and dewatering has become increasingly important in recent years. Firstly, water is an important resource. This can make the difference between 'yes, we can operate' or 'no, we cannot'. Secondly, filtered tailings can be stacked, which is safer, cheaper and environmentally more acceptable. Thirdly, especially with mine backfill, the amount of cement to be added can be reduced, which may save millions of dollars per year. For the efficiency and safety of the tailings treatment, it is therefore crucial that the employed dewatering technology can meet the requirements for the dewatering result reliably and economically.

Typically, pressure filters, filter presses, belt filters and rotary vacuum disc filters are used for this dewatering duty. Among these technologies, in more than $80 \%$ of all applications, the vacuum disc filter type is assumed to be the most economical solution with reference to both capital and operating cost aspects, especially when modern disc filters are used. A characterising outline and a comparison of capital and operating data of these technologies have been presented by Hahn et al. (2014a).

When it comes to achieving higher filtration rates, or to achieve the necessary tailings filter cake moisture for stacking, the continuous HiBar filtration and HiBar steam pressure filtration offer new solutions in tailings dewatering. 


\section{Typical properties of tailings}

Tailings from ore processing are generally non-valuable products that must be disposed of in an environmentally sound, secure and economical way. Typical properties of tailings, with respect to filtration, can be summarised as follows:

- Tailings contain very fine particle sizes, mostly in the range of $d_{50}$ of 10 micron up to 100 micron.

- The formed filter cakes have a sticky behaviour and are difficult to release from filter fabric.

- The $\mathrm{pH}$ value is often low or high, making the tailings often corrosive.

- Solids content is typically in the range of 50-70 wt\% after thickening.

- Clay content (depending on the orebody) can hinder filtration and dewatering.

\section{How far do you have to go - filtration makes the difference}

Depending on the requirements for surface stacking or mine paste backfill, specific filter cake target moisture can be achieved by the filtration equipment.

The typical application field of vacuum disc filters can generally be specified by the following range with regard to the required filter cake moisture of $<18 \mathrm{wt} \%$ to $22 \mathrm{wt} \%$.

When filtered tailings stacking requires filter cake moisture of $<18 \mathrm{wt} \%$, then vacuum filtration is not able to meet these goals. Such target values can only be achieved by means of pressure filtration or the HiBar filtration.

HiBar filtration and the HiBar steam pressure filtration are advanced continuous pressure filtration processes realised on rotary disc filters that are installed in a pressure vessel. When higher filtration rates, or the lowest filter cake moisture for stacking must be achieved, then the HiBar filtration and HiBar steam pressure filtration offer new solutions in tailings dewatering.

\section{Design of the Boozer high performance vacuum disc filter}

With the high performance Boozer disc filter, BOKELA has developed a new generation of big diameter disc filters (Figure 1) that have set a new standard for seed filtration in the alumina industry and in dewatering coal slurries. This type of disc filter is being used frequently in paste dewatering applications.

The outstanding hydraulic characteristics of these modern disc filters were achieved by improving each detail of the filter design, leading to extraordinarily high performance capacity, high operational safety and reliability, and low maintenance and operation costs. The main features of this new disc filter generation are as follows:

- Minimised pressure drops leading to up to $100 \%$ higher pressure difference at the filter cloth compared to vacuum disc filters of the old design.

- Double capacity compared to conventional disc filters.

- High filter speed of $6 \mathrm{rpm}$.

- High operational reliability and flexibility.

- Easy maintenance.

- Fully automatic and safe operation due to the superior process philosophy realised in a programmable logic controller system. 


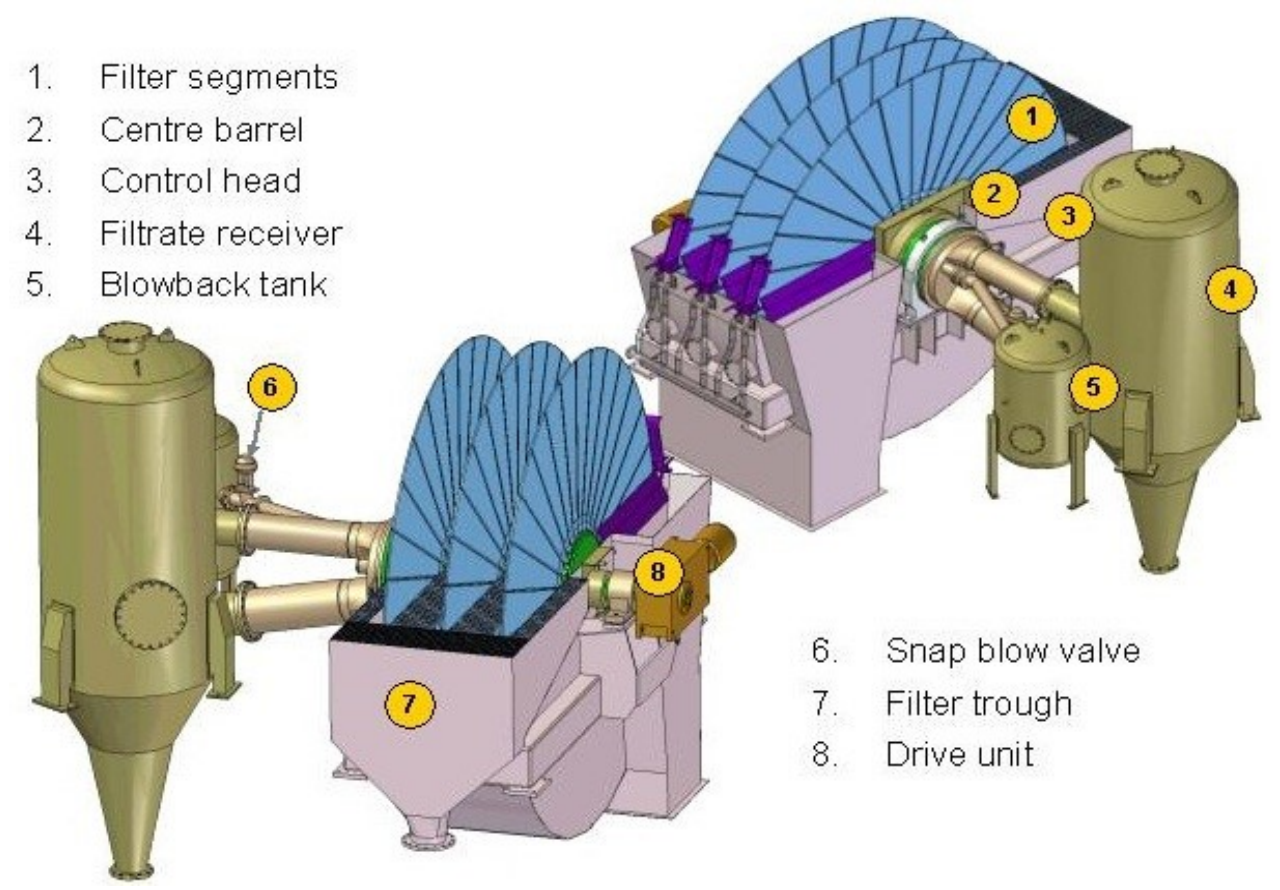

Figure 1 View of a Boozer disc filter with three discs

Disc diameters range from 1.7 to 4.2 and up to $5.6 \mathrm{~m}$. For filtration of large slurry feed rates, such as tailings, a filter with a large disc diameter of $5.6 \mathrm{~m}$ (L-type) is the appropriate filter size; this is available with one to four filter discs. A more detailed description is given by Hatzenbühler et al. (2013).

These disc filters can be operated in a fully automated mode and thus can react online to changes in the filtration properties of the thickened tailings to maintain the required moisture. Furthermore, modern disc filters are very reliable about cake discharge, no matter how much fines are fed or how the feed solids content changes. The operation, even with high amounts of fines and the constant cake moisture, allows use of tailings for mine backfill without the need to split it into fine or coarse fractions. This reduces the process equipment required, the investment cost and the amount of cement added to the tailings.

\subsection{Redesign of the Boozer}

After 25 years of operational experience with numerous filter units in many industries, BOKELA has redesigned and upgraded the Boozer based on feedback from the operator. It was the target to improve the high standards that operators associate with the Boozer by simultaneously reducing cost and weight. The motto of the new design was 'high performance for less money'. To achieve this aim, the proven and successful Boozer filter design has been enhanced by a series of new design features and improvements. The following targets have been the guideline for the new design:

- High, same or even increased performance capacity.

- Light filter segment made of polymer considerably below $15 \mathrm{~kg}$.

- Reduction of total weight of a filter unit.

- Further improvement of filter operation and maintenance.

- Significant cost reduction.

A detailed description of the new design is given by Hahn et al. (2015). 


\subsection{Lightweight filter segment}

The new lightweight, snap-on filter segment (Figure 2) is made of fibre-reinforced polymer (FRP). With this novelty, BOKELA responded to a long-time objective of operators who have always desired a lightweight filter segment for easy handling.

Weighing less than $10 \mathrm{~kg}$, the new filter segment facilitates lifting and re-clothing for one person with ease and no need for cranage.

Characteristics and benefits of the new lightweight filter segment:

- Less than $10 \mathrm{~kg}$ in weight.

- Facilitates lifting and re-clothing for one person with ease and no need for cranage.

- Snap-on design - mounting and dismounting of segments nearly without tools.

- Excellent internal hydraulics to ensure fast filtrate drainage, which is decisive for high performance.

- Made of FRP.

- Reduced cost per unit.

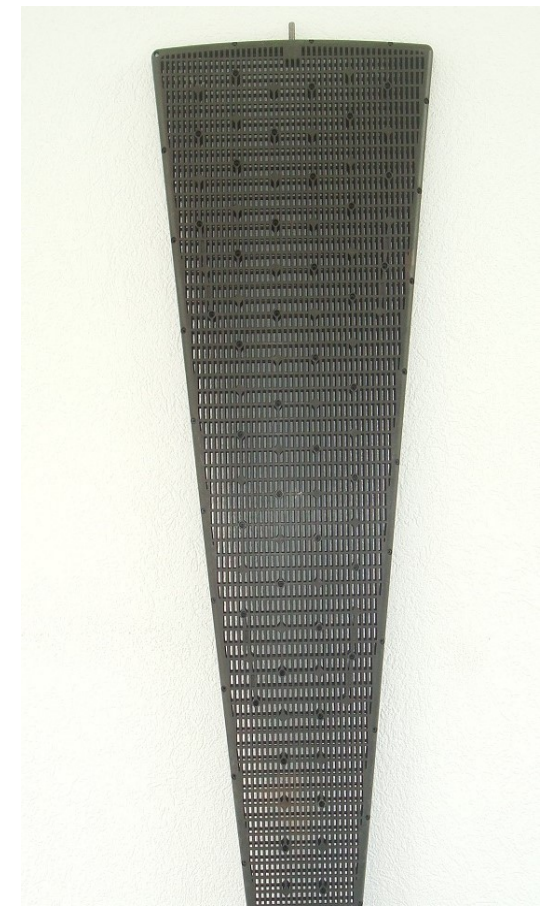

(a)

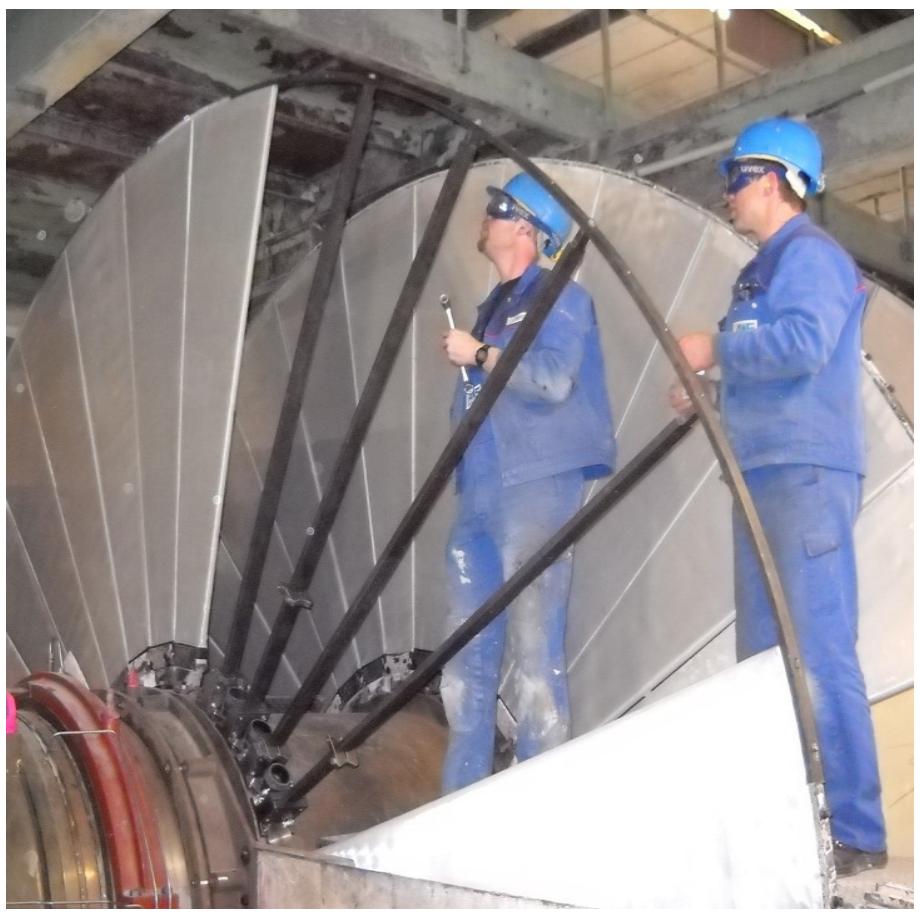

(b)

Figure 2 New lightweight snap-on segment of (a) $<10 \mathrm{~kg}$ in weight; (b) Mounting of new segments onto a Boozer disc filter

\subsection{Conditions for use of a vacuum disc filter in tailings dewatering}

Vacuum disc filters are suitable for applications of tailings dewatering where the following conditions and targets apply:

- If the clay content in the solids is low.

- If the tonnage is $>50 \mathrm{t} / \mathrm{hr}$ and big filter sizes can be applied.

- If a moisture of $>18 \mathrm{wt} \%$ is accepted. 
- If energy efficiency is important.

- If there is a space constraint.

- If limited operator expertise is available.

- If the amount of flocculent is to be minimised.

- If operational costs are to be minimised.

\subsection{Exemplary references of tailings dewatering with the Boozer vacuum disc filter}

\subsubsection{Dewatering of gold/copper tailings}

The first Boozer vacuum disc filter for tailings dewatering started operation in 2010 at the Chelopech mine in Bulgaria where the tailings are used for mine backfill (Figure 3). For this application, a Boozer L4 disc filter with $176 \mathrm{~m}^{2}$ of filter area and a $5.6 \mathrm{~m}$ disc diameter is in operation. The implementation of the Boozer L4 disc filter for this dewatering duty was part of the mine upgrading and modernisation project when Chelopech switched the mining method away from the environmentally challenging caving method to a drill and fill method (Liston 2014) to increase production rate, production reliability and sustainability.

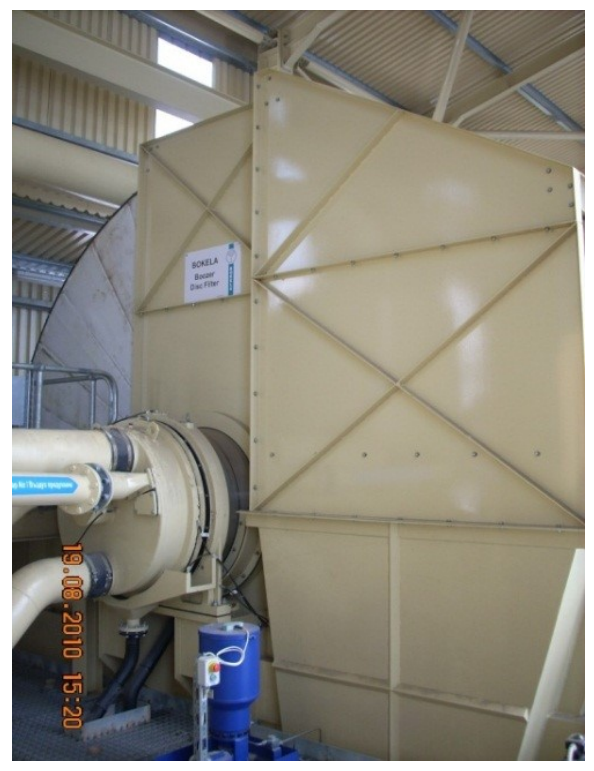

(a)

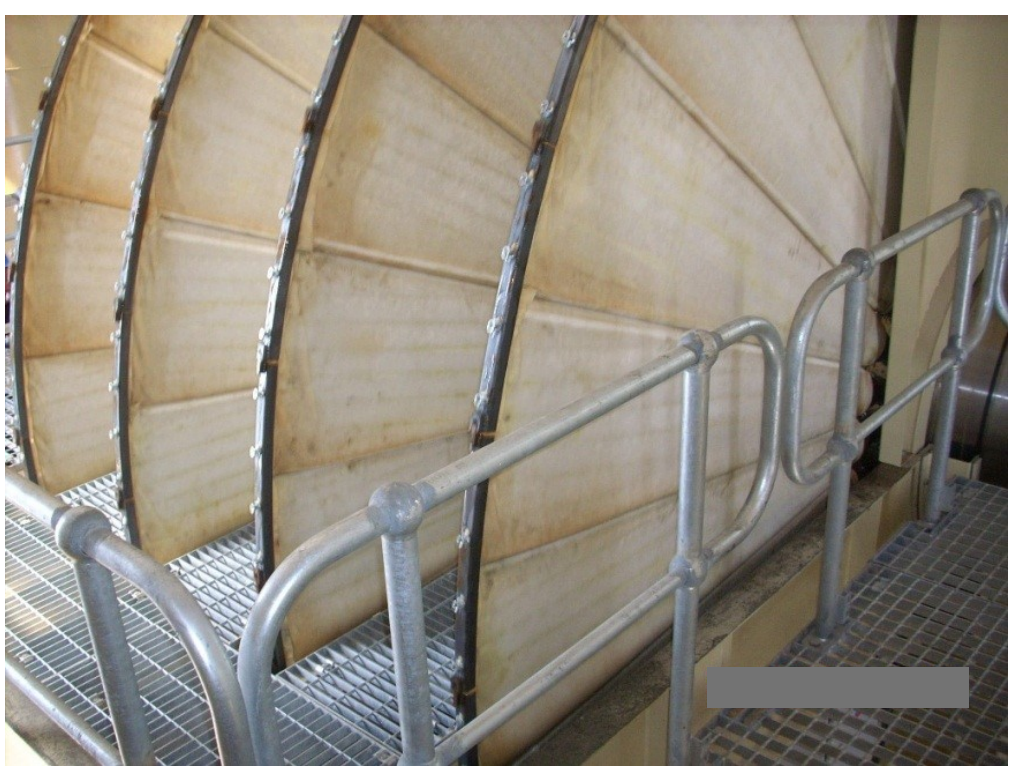

(b)

Figure 3 Disc filter (176 $\mathrm{m}^{2}$ filter area) assembled in the gold/copper mine. (a) View of control head side; (b) View of the four filter discs with walkways

During layout tests, the tailings consisted of particles with a mean diameter size of $d_{50}$ of 20-30 microns and were thickened to $>50 \mathrm{wt} \%$. Target value for solids throughput was specified to $100 \mathrm{t} / \mathrm{hr}$ and target cake moisture was specified to $23 \mathrm{wt} \%$. Layout tests showed that the required $100 \mathrm{t} / \mathrm{hr}$ solids throughput could be achieved with one disc filter of $176 \mathrm{~m}^{2}$ of filter area, which requires a minimum filtration rate of $568(\mathrm{~kg} / \mathrm{hr}) / \mathrm{m}^{2}$ to ensure target solids throughput of $100 \mathrm{t} / \mathrm{hr}$.

Since filter commissioning, the characteristics of the slurry have changed especially with respect to particle size distribution. The mean particle diameter $d_{50}$ increased from $25 \mu \mathrm{m}$ to $40 \mu \mathrm{m}$ and the filtration rate increased to rates higher than needed. Therefore, flocculent dosage could be reduced stepwise and the filter can be operated even without flocculent. The achieved filter performance is $110 \mathrm{t} / \mathrm{hr}$ for solids throughput rates and residual cake moisture ranges from 19 to $22 \mathrm{wt} \%$. After nearly six years of operation, the filters are in excellent condition thanks to the preventive maintenance concept of the plant.

A more detailed description of this application is given by Hatzenbühler et al. (2013). 


\subsubsection{Dewatering of zinc tailings}

For dewatering of zinc tailings from a copper and zinc mine in Queensland, Australia, two Boozer ME8 disc filters have been installed and started operation in 2014 (Figure 4). Each filter has a filter area of $141 \mathrm{~m}^{2}$ and consists of eight filter discs with a diameter of $4.1 \mathrm{~m}$.

This project was started in 2004 when the client ordered a filter assessment to investigate the options of a capacity increase of the paste plant by retrofitting the existing vacuum disc filters. The paste plant operated two vacuum disc filters for zinc tailings dewatering. Each filter was filtering about $120 \mathrm{t} / \mathrm{hr}$ of tailings (on a dry solids basis) and both filters were treating about $240 \mathrm{t} / \mathrm{hr}$ while the total plant capacity of tailings was $350 \mathrm{t} / \mathrm{hr}$. In 2013, the project was finally launched. Now the target was to replace the existing two filters with two new filters to meet the total plant capacity of $350 \mathrm{t} / \mathrm{hr}$ of tailings. This is an almost $50 \%$ capacity increase on basically the same filtration area. It was essential that the two filters should fit into the existing filter floor space with a minimum of modification work. The new operating data of the two existing filters have been compared with the filter assessment back in 2004 and have shown a good relation. Additionally, a site visit of a BOKELA expert has confirmed filter operations compared favourably with operations in 2004. Based on this, two new Boozer ME8 disc filters were chosen for the replacement project and were commissioned in 2014.

The tailings slurry mainly consists of silicates. Product characteristics of the feed slurry and target values with respect to solids throughput and cake moisture are as follows:

- Feed solids concentration of 60-65 wt\%.

- Particle size distribution with a mean particle diameter $\mathrm{d}_{50}$ of $50 \mu \mathrm{m}$.

- Target solids throughput on dry solids basis: $350 \mathrm{t} / \mathrm{hr}, 175 \mathrm{t} / \mathrm{hr}$ per filter.

- Target filter cake moisture of 20-22 wt\%.

In Table 1, both the expected performance values and operational values of the running filters are shown.

The two-disc filters are operated fully automatic. Filter start-up, filter operation and filter shut down are carried out automatically. An automatic filter operation control adapts filter performance to changing slurry and process conditions and avoids emergencies. The design and the outstanding hydraulic capacity of the Boozer vacuum disc filters is the basis of the specific operation philosophy for improved filter operation without continuous slurry overflow (Hahn et al. 2011).

Table 1 Expected and achieved operational values of solids throughput and cake moisture

\begin{tabular}{|c|c|c|c|}
\hline Dewatering of zinc tailings & & Predicted value per filter & Operational value per filter \\
\hline \multicolumn{4}{|l|}{ Solids throughput } \\
\hline Normal & $\mathrm{t} / \mathrm{hr}$ & 175 & $>175$ \\
\hline Peek design & $\mathrm{t} / \mathrm{hr}$ & 200 & 210 \\
\hline $\begin{array}{l}\text { Filter speed for normal } \\
\text { operation }\end{array}$ & $\mathrm{rpm}$ & 1.5 & $\leq 1$ \\
\hline Cake moisture & wt\% & $20-22$ & $17-20$ \\
\hline Flocculent dosage & $\mathrm{g} / \mathrm{t}$ dry solids & depending on feed & $0-50$, depending on feed \\
\hline
\end{tabular}




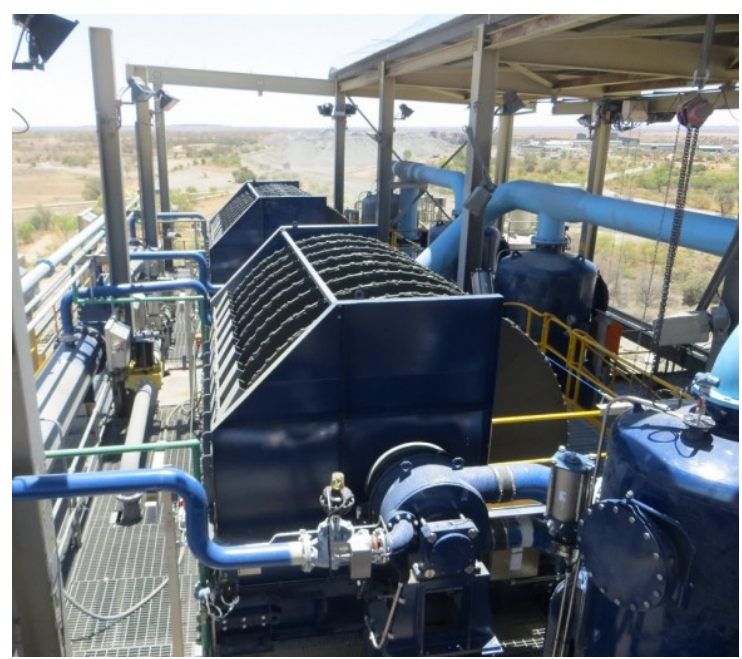

(a)

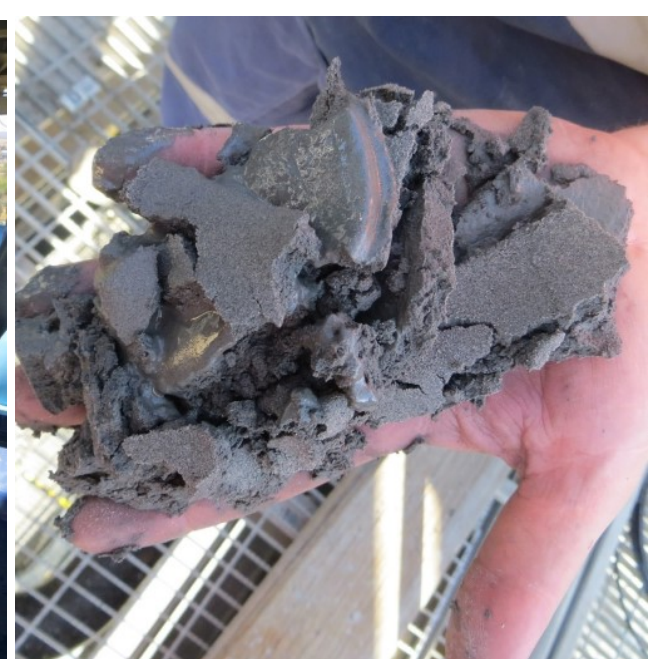

(b)

Figure 4 Two Boozer disc filter ME8 (141 $\mathrm{m}^{2}$ filter area each) for: (a) Zinc tailings dewatering in the filter building; (b) Discharged filter cake

Depending on the slurry feed, the discharged filter cake may be too dry for downstream processing in the mixer. This can be prevented by throttling the dewatering vacuum, which increases the moisture of the filter cake. Experiences gained from the filter commissioning and filter operation are summarised to following recommendations to ensure safe and reliable filter operation:

- The exact mounting and fixation of the filter bags onto the filter segments to prevent solids from penetrating into the filtrate piping.

- Routine inspections by a well-trained operator and maintenance team:

○ to detect defective filter bags, which should be replaced as prompt as possible.

o to detect initiating damages through the abrasiveness of the slurry in an early stage.

\subsubsection{Dewatering of tailings from a gold/silver mine at 4,800 $\mathrm{m}$ above sea level}

For dewatering of tailings from a gold/silver mine in Peru, two Boozer L4 disc filters (Figure 5) have been installed and started operation in March 2016. Each filter has a filter area of $176 \mathrm{~m}^{2}$ and four filter discs of $5.6 \mathrm{~m}$ disc diameter. The filtered and dewatered tailings will be mixed with cement and will be backfilled into the exploited mine areas.

A worldwide operating engineering company was looking for filtration equipment to dewater these tailings coming from a gold/silver mine that is located $4,800 \mathrm{~m}$ above sea level (masl). This was a big challenge as the client was looking for a cost-efficient filtration solution. On the one hand, it was required from the equipment to have a small footprint for reducing building costs and logistic efforts to get all the parts in the remote area of the plant site. Basically, this took the option for four large vacuum belt filters out of the focus and favoured pressure filtration. On the other hand, the filtration equipment was required to be low in operation cost as electricity is limited and the overall operating expense should be as low as possible. This disqualified the pressure filtration option. As a result, the high performance Boozer disc filter fulfilled both requirements in the optimal way and was chosen to be the most suitable dewatering technology for this application. 


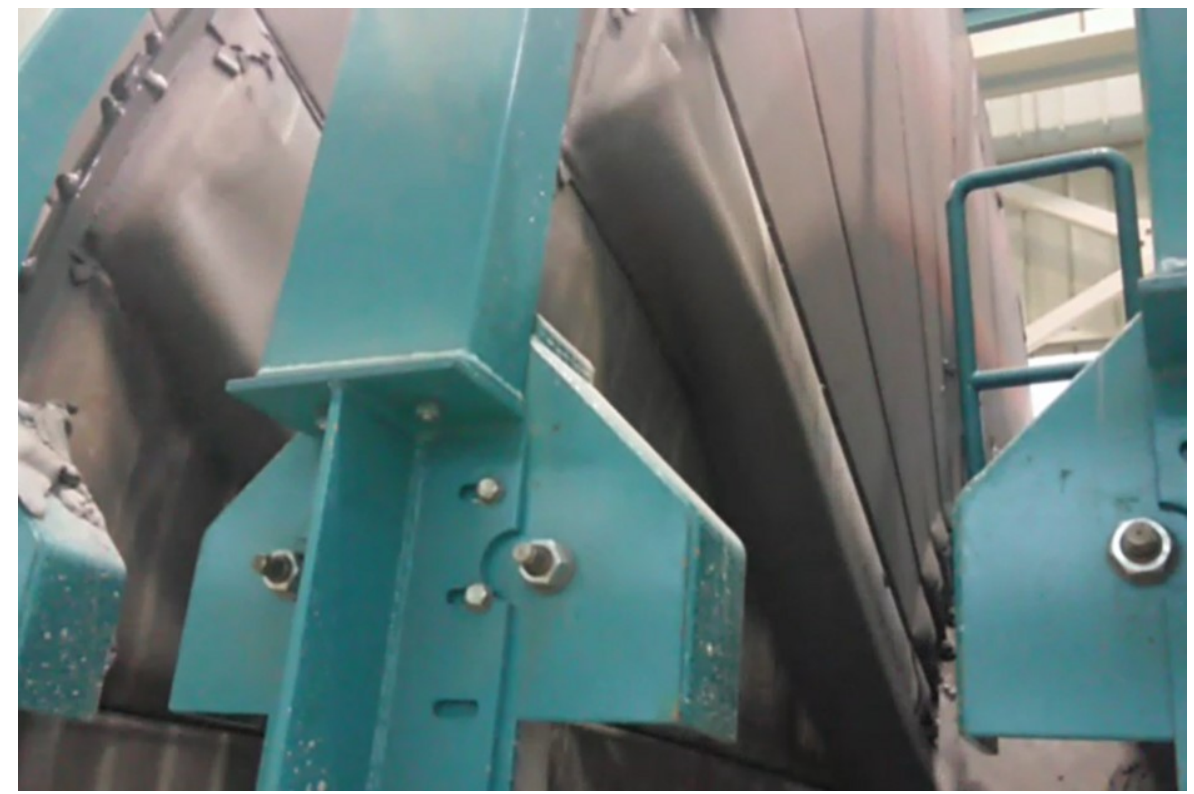

Figure 5 Tailings dewatering from a gold/silver mine with a Boozer disc filter L4 (176 $\mathrm{m}^{2}$ filter area) complete cake discharge during commissioning

Product characteristics of the feed slurry are as follows:

- Feed solids: $60 \mathrm{wt} \%$ solids.

- Particle size distribution $d_{20} / d_{50} / d_{80}: 6.7 \mu \mathrm{m} / 22 \mu \mathrm{m} / 52 \mu \mathrm{m}$.

- $\mathrm{pH}$ value: 11 .

Based on filtration test work conducted by a third party and the experience of BOKELA in the field of tailings filtration, the following filter layout has been made:

- Solids throughput on a dry solids basis: $88 \mathrm{t} / \mathrm{hr}$ and $44 \mathrm{t} / \mathrm{hr}$ per filter.

- Cake moisture content: $<20$ wt\%.

- Flocculent dosage: $10-50 \mathrm{~g} / \mathrm{t}$ dry solids.

The two-disc filters will be operated in a fully automatic way. That is, filter start-up, filter operation and filter shut down are carried out automatically. The first test during the pre-commissioning phase proved that the filter can be operated within the required and predicted performance range.

\section{$5 \quad$ Lowest moisture contents for improved dry stacking with HiBar filtration}

The HiBar filtration and HiBar steam pressure filtration are advanced continuous pressure filtration processes realised on rotary disc filters that are installed in a pressure vessel. The application of hyperbaric pressure of up to 6 bar (instead of a vacuum) ensures a high filtration rate and dewatering capability even with slurries with fine particles. The HiBar steam pressure filtration uses steam under special conditions. This advanced hybrid dewatering process improves the dewatering to such an extent that the lowest possible filter cake moistures can be achieved. The drier HiBar filter cakes improved filter cake handling and disposal with steeper dumping slopes, and therefore reduced the disposal area required and improved the safety of the disposal site.

In the past, BOKELA HiBar steam pressure filtration has been particularly popular in the chemical industry. For more than 15 years, customers in this industry have enjoyed the excellent process results, high reliability and economic feasibility in a wide range of applications this technology has to offer. In recent 
years, this process technology has become increasingly interesting for other applications such as in the dewatering of bauxite residue (Hahn et al. 2014b) or the dewatering of coal ultrafines (Hahn at al. 2016).

\subsection{Plant and process design of HiBar filtration technology}

The HiBar filtration technology uses a rotary disc filter installed inside a pressure vessel (Figure 6) filled with compressed air at up to 7 bar absolute. The filtrate pipes are connected to the environment and the suspension is pumped by an appropriate pump into a pressurised vessel. The filter cake is removed from the filter cloth by compressed air blowback and discharged from the pressurised zone through a sluice system. The vacuum pumps used with a conventional vacuum filter are replaced by a compressor that supplies the necessary compressed air to the vessel and for compressed air blowback. The compressed air from cake blowback also serves as process air to maintain the hyperbaric pressure in the vessel for the filtration process. Inside the vessel, the filter runs with a differential pressure of up to 6 bar. For the discharge of the filter cake out of the vessel, discharge sluices (double chamber sluice with gate valves) of advanced design are used.

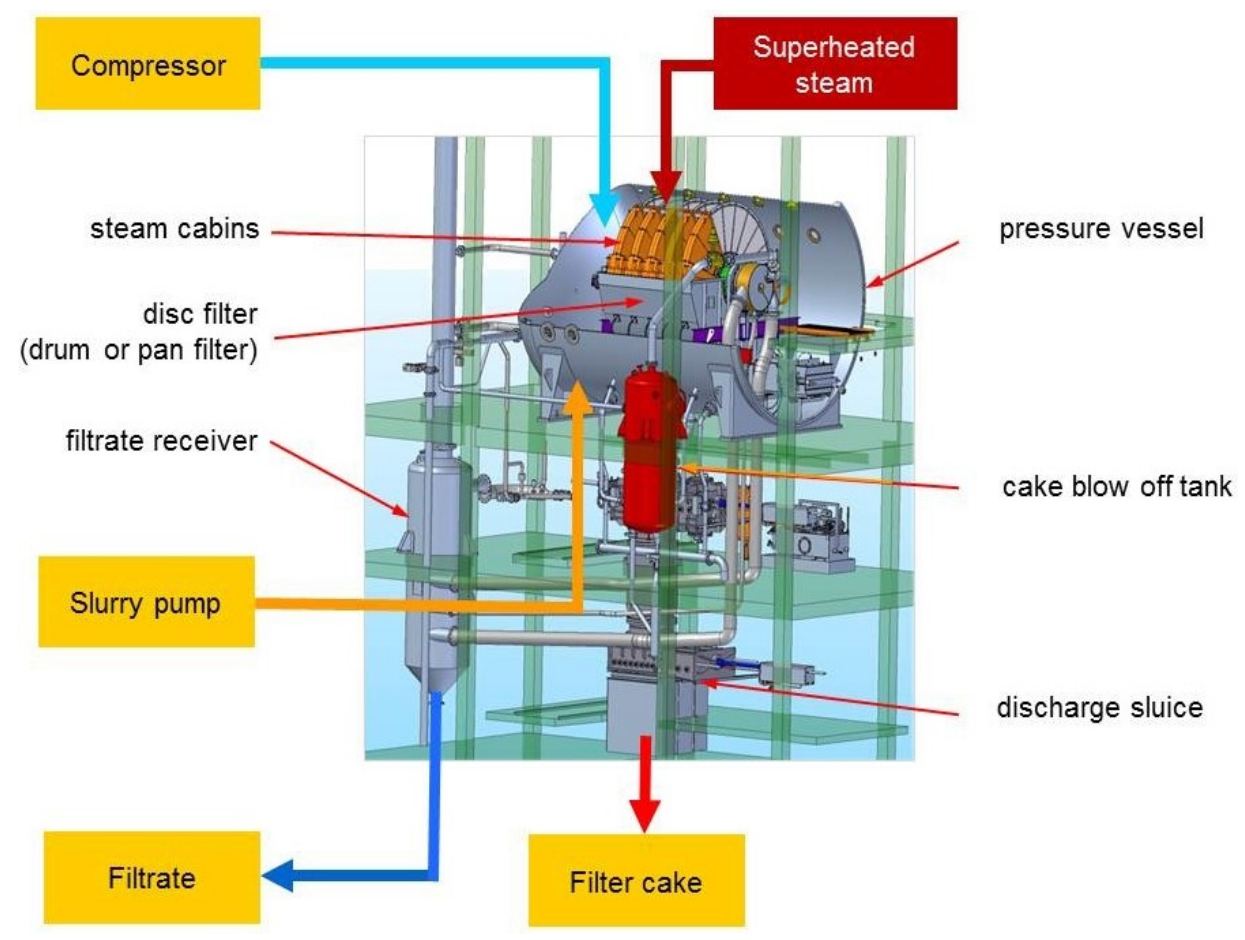

Figure 6 Plant design of HiBar filtration technology

The use of the high differential pressure of up to 6 bar (instead of a vacuum) ensures a high specific throughput and dewatering capability even with slurries of fine particles where a high filter cake resistance and high capillary forces in the cake have to be overcome. The higher the differential pressure, the higher the solids throughput capacity and the smaller the capillaries of a filter cake can be dewatered by the compressed air. Accordingly, lower moisture contents are achieved.

Filter sizes range up to $168 \mathrm{~m}^{2}$ for one disc filter unit. An industrial HiBar steam pressure filtration plant with a $70 \mathrm{~m}^{2}$ disc filter is shown in Figure 7. 


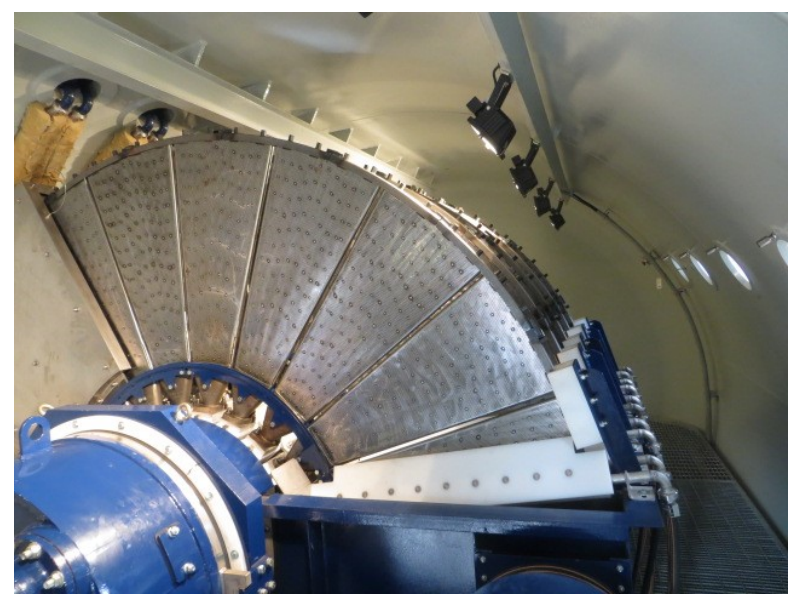

(a)

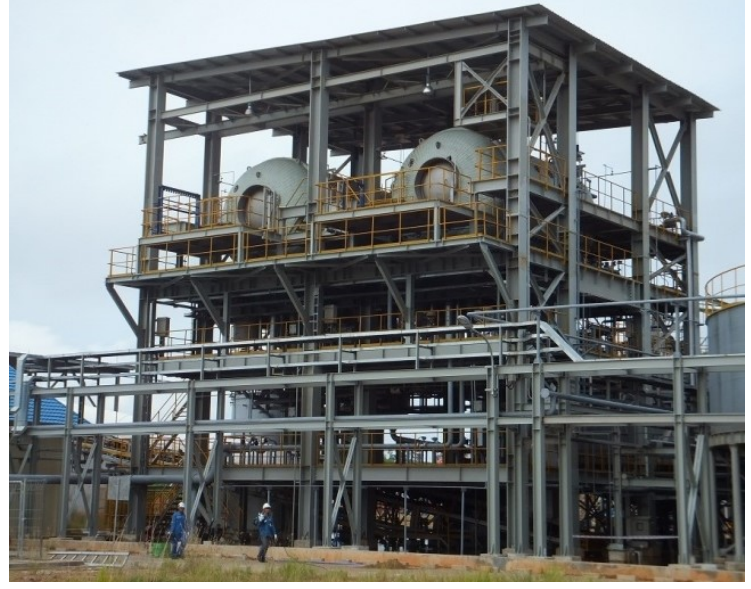

(b)

Figure 7 HiBar hyperbaric disc filters (70 $\mathrm{m}^{2}$ each) with steam cabins for: (a) Steam pressure filtration in pressure vessel; (b) Filter building with two HiBar hyperbaric disc filters $70 \mathrm{~m}^{2}$ each

\subsubsection{HiBar steam pressure filtration technology}

For steam pressure filtration, the filter discs are equipped with specially designed and patented steam cabins and with feed pipes for steam supply. The use of steam for the continuous HiBar steam pressure filtration technology leads to a combined thermal/mechanical phenomenon during filter cake dewatering followed by a subsequent convective drying with pressurised gas (Gerl \& Stahl 1996).

In HiBar steam pressure filtration, the filter cake is only partially exposed to steam, which accelerates and intensifies the dewatering. This condensate front process can be explained as follows.

A filter cake that is formed at the low temperature of the feed slurry enters a specially designed steam cabin immediately after emerging from the slurry in the filter trough. Here, a superheated steam atmosphere exists, and the following phenomena (which can be described by the model of the 'condensate front' (Figure 8)) take place:

- The steam condenses on the cold cake surface and a homogeneous condensate layer is formed and moves through the cake in a piston-like flow (condensate front).

- The moving condensate front replaces nearly $100 \%$ of the 'mother liquor'.

- When the condensate front reaches the filter cloth, the filter cake is 'heated' completely to the steam temperature. At this point, the cake leaves the steam cabin.

- Compressed air passes the pre-dewatered and hot filter cake causing a very effective thermal drying, which leads to extremely low cake moisture contents (Figure 9). 


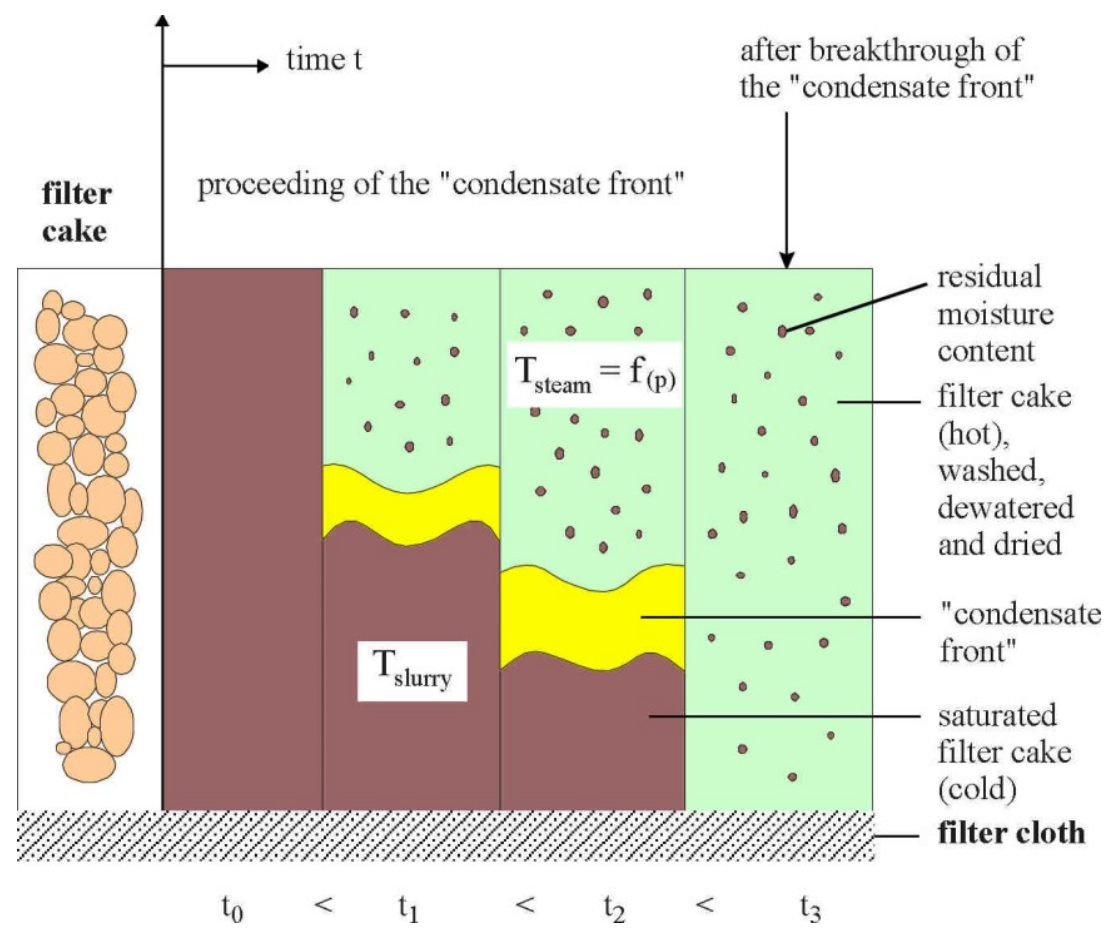

Figure 8 Hyperbaric steam pressure filtration technique: model of the 'condensate front'

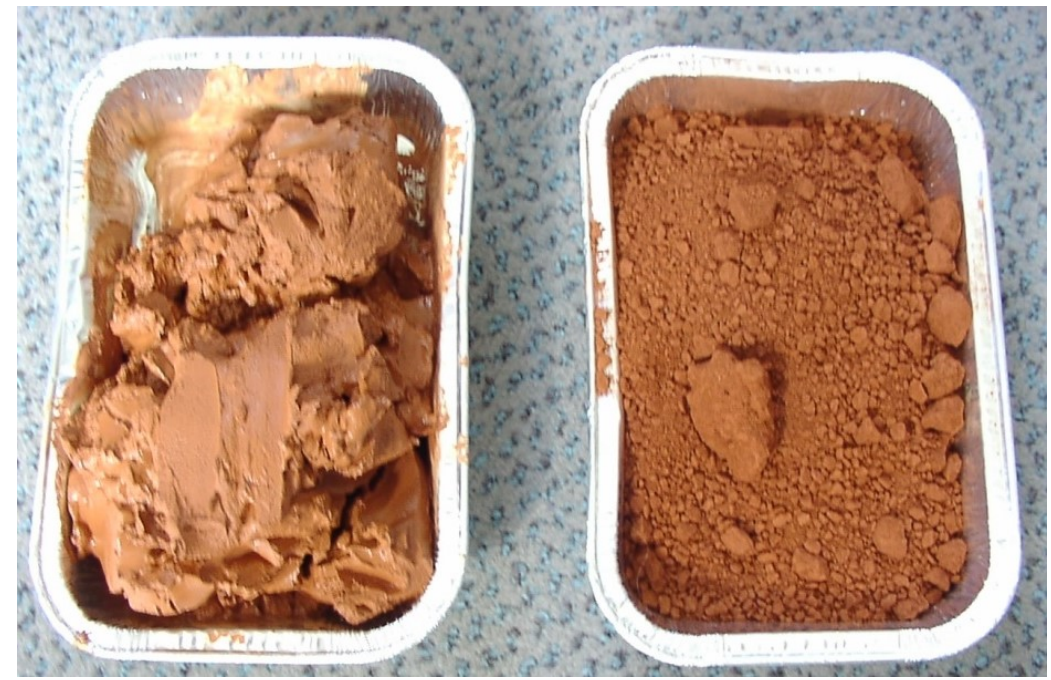

Figure 9 Filter cakes of bauxite residue: (a) Pasty and sticky from vacuum filtration; (b) Sandy material from HiBar steam pressure filtration

These thermal/mechanical processes inside the cake intensify and accelerate the dewatering leading to a nearly homogeneous and highly intensive cake demoisturing without pressure and energy loss by so-called 'fingering'. This phenomenon occurs when the compressed air preferably flows through the large pores of the filter cake, which are dehydrated more easily and quickly. Since the small pores, which have a larger flow resistance, are not dehumidified, this means a loss of pressure and energy without further dewatering success.

\subsection{Dewatering of tailings with HiBar disc filtration technology}

When higher filtration rates are required or when filtered tailings stacking requires a low moisture of $<18 \mathrm{wt} \%$, the HiBar hyperbaric filtration and HiBar hyperbaric steam pressure filtration offer new solutions in tailings dewatering. The achievable values with regard to solids throughput and moisture content depend on the specific characteristics of the individual tailings slurry. Reliable data for a filter layout has to 
be determined by filtration tests. In general, the ranges for tailings filtration achievable with HiBar filtration are listed in Table 2.

Table 2 Footprint and expected values of solids throughput and cake moisture for tailings filtration achievable with HiBar filtration

\begin{tabular}{ll}
\hline Footprint & Expected value \\
\hline Filter cake moisture & $<18 \mathrm{wt} \%$ \\
& $250 \mathrm{t} / \mathrm{hr}$ per unit (disc filter with $168 \mathrm{~m}^{2}$ ) with 1 discharge sluice \\
Solids throughput & $500 \mathrm{t} / \mathrm{hr}$ per unit (disc filter with $168 \mathrm{~m}^{2}$ ) with 2 discharge sluices \\
Footprint per unit & $200 \mathrm{~m}^{2}\left(20 \times 10 \mathrm{~m}\right.$ ) for disc filter plant with $168 \mathrm{~m}^{2}$ filter area \\
\hline
\end{tabular}

The data given in Table 2 illustrates that HiBar hyperbaric filtration is an option for tailings dewatering, which not only achieves filter cakes with low residual moisture, but also makes it possible to handle large quantities of tailings with a modest number of filter units. For example, for a solids throughput of 2,000 t/hr, only four HiBar hyperbaric filter units would be required.

When the solids become finer and the dewatering characteristics of the filter cake become worse, the application of steam, if the unit is prepared for steam pressure filtration, will ensure the required moisture to be safely achieved. In such cases, HiBar filtration ensures constant cake moisture with constant solids throughput performance.

\section{Conclusion}

Each filtered tailings stacking or mine backfill dewatering application has a specific filter cake target moisture to be achieved by the filtration equipment. The Boozer disc filter has set the standard in a multitude of applications in many industries, such as the alumina industry and in dewatering coal slurries. In the recent past, this modern high performance disc filter has established itself increasingly in tailings dewatering applications, especially (but not exclusively) with the dewatering of mine backfill. Among competitive technologies (such as pressure filters, filter presses and belt filters) vacuum disc filters of modern design are the most economical solution with reference to both capital and operating cost in a wide range of tailings applications. When it comes to achieving higher filtration rates, or to achieve the lowest possible filter cake moisture for filtered tailings stacking, the HiBar filtration and HiBar steam pressure filtration technologies offer new solutions. These advanced continuous pressure filtration processes can handle larger quantities of tailings with a modest number of filter units.

\section{Acknowledgement}

We would like to thank our customers for their trust in our technologies and their kind support.

\section{References}

Gerl, S \& Stahl, W 1996, 'Improved dewatering of coal by steam pressure filtration', Coal Preparation, vol. 17, issue 1-2, pp. 137-146.

Hahn, J, Bott, R \& Langeloh, T 2011, 'Paste dewatering with the Boozer disc filter', in RJ Jewell \& AB Fourie (eds), Proceedings of the 14th International Seminar on Paste and Thickened Tailings, Australian Centre for Geomechanics, Perth, pp. 45-56.

Hahn, J, Bott, R, \& Langeloh, T 2014a, 'Economical dewatering of tailings for mine backfill with high performance disc filters', in Y Potvin \& T Grice (eds), Proceedings of the 11th International Symposium on Mining with Backfill, Australian Centre for Geomechanics, Perth, pp. 41-48.

Hahn, J, Bott, R \& Langeloh, T 2014b, 'Successful start-up of first HiBar steam pressure filtration plant for dry bauxite residue (DBR)', The 32nd International Conference and Exhibition of ICSOBA, The International Committee for Study of Bauxite, Alumina \& Aluminium, Quebec.

Hahn, J, Bott, R \& Langeloh, T 2015, 'Size matters, weight too - disc filter design for the future', Proceedings of the 10th Alumina Quality Workshop, AQW Inc., Eagle Farm. 
Hahn, J, Bott, R \& Langeloh, T 2016, 'HiBar steam pressure filtration of coal ultrafines - new developments and results', in V Litvinenko (ed.), Proceedings of the 16th Australian Coal Preparation Society Conference, Springer, Wollongong.

Hatzenbühler, M, Hahn, J, Bott, R \& Langeloh, T 2013, 'Dewatering of tailings for mine backfill with the Boozer disc filter', in RJ Jewell, AB Fourie, J Caldwell \& J Pimenta, Proceedings of the 16th International Seminar on Paste and Thickened Tailings, Australian Centre for Geomechanics, Perth, pp. 419-430.

Liston, D 2014, 'Utilisation of cemented rockfill, cemented hydraulic fill and paste to successfully achieve ore production expansion to 2 Mtpa at Chelopech Mine', in Y Potvin \& T Grice (eds), Proceedings of the 11th International Symposium on Mining with Backfill, Australian Centre for Geomechanics, Perth, pp. 407-420. 
filter cake moisture for filtered tailings stacking 